\title{
SIMULAÇÃO E ANÁLISE ECONÔMICA DA PRODUÇÃO DE BIODIESEL A PARTIR DE ÓLEO DE MACAÚBA
}

\author{
R. P. CRUZ ${ }^{1}$, F.B. FERREIRA ${ }^{2}$ e F.Á. RODRIGUES ${ }^{3}$ \\ ${ }^{1}$ Universidade Federal de Viçosa, Departamento Química \\ ${ }^{2}$ Universidade Federal de Viçosa, Departamento Química \\ ${ }^{3}$ Universidade Federal de Viçosa, Departamento de Química \\ E-mail: rodolfo_pinheiro@hotmail.com
}

\begin{abstract}
RESUMO: Este trabalho teve por objetivo a simulação de três plantas de produção de biodiesel via transesterificação etílica, utilizando o óleo de macaúba como fonte de triglicerídeos, todas simuladas no software Aspen HYSYS 8.8. As plantas foram projetadas para operar com uma vazão de $1000 \mathrm{~kg} \mathrm{~h}^{-1}$ de óleo e as rotas utilizadas foram a Catálise Homogênea Ácida, Catálise Homogênea Básica e Transesterificação em meio Supercrítico, o biodiesel produzido atendeu tanto as exigências da Agência Nacional do Petróleo (ANP) quanto da American Society for Testing and Materials (ASTM). Realizou-se também uma análise de viabilidade econômica para as plantas simuladas, estimando, a partir delas, o custo de produção do biodiesel, sendo estes para as plantas operando por catálise ácida, básica e meio supercrítico US\$1,50, US\$1,77 e US\$1,59 respectivamente. Por fim uma análise de sensibilidade foi feita a fim de observar o efeito da variação do preço e da vazão do óleo sob os custos de produção do biodiesel.
\end{abstract}

PALAVRAS-CHAVE: Biodiesel; Macaúba; Aspen Hysys; Simulação; Análise Econômica.

\section{INTRODUÇÃO}

A matriz energética mundial ainda é predominantemente composta por combustíveis de origem fóssil tais como petróleo, gás natural e seus derivados, entretanto já há sinais de esgotamento das reservas desses combustíveis, o que pode gerar impactos sérios na economia mundial e também insegurança energética (SHAFIEE e TOPAL, 2009). A preocupação com o meio ambiente também se apresenta como um dos problemas ligados a este tipo de reserva, uma vez que os combustíveis fósseis são os principais responsáveis pelos gases associados às mudanças climáticas (DEMIRBAS, 2008). Dessa forma a busca por alternativas mais viáveis e menos agressivas ao meio ambiente intensificou-se e com isso os combustíveis de fontes renováveis acabaram se destacando. 
Entre os biocombustíveis, o biodiesel se consolida como uma forte alternativa, tanto pelo lado econômico quanto pelo lado ambiental, apresentando grande potencial de crescimento para substituir o diesel do petróleo (GIRARDI, 2015). O uso do biodiesel como combustível veicular já é regulamentado desde 2005 e apresenta evolução notável devido a políticas de aumento de sua adição na mistura com o diesel mineral. Entre as principais vantagens do biodiesel em relação ao petróleo estão o fato de ele ser renovável, apresentar menor emissão de gás carbônico, não ser tóxico, além de diminuir o desgaste das partes móveis do motor e ser um melhor lubrificante (RAMADHAS et al., 2004).

Para o biodiesel tornar-se viável economicamente é necessário encontrar uma fonte de óleo de baixo custo. A macaúba aparece como uma alternativa de grande potencial, sua produtividade de óleo pode chegar a $4220 \mathrm{~L}_{\text {há-1 }}$. Além da elevada produtividade, a macaúba tem outras vantagens que a tornam atrativa. Do ponto de vista social, essa cultura gera muitos empregos, tanto o cultivo quanto o plantio requerem o uso de mão de obra manual (CARVALHO et al., 2013). Pelo aspecto ambiental e da sustentabilidade, ela pode ser usada na recuperação de áreas degradadas (QUINTANA et al., 2013); é capaz de absorver grandes quantidades de $\mathrm{CO}_{2}$ da atmosfera (FERREIRA et al.,2013); se adapta a solos pobres (LORENZI e NEGRELLE, 2006); pode ser cultivada em conjunto com outras culturas; e por ser uma cultura perene, requer menor uso de adubos e defensivos agrícolas. Por fim, analisando pelo lado econômico, ela é uma atividade lucrativa para os produtores agrícolas (PIMENTEL et al., 2011).

O biodiesel é mais comumente produzido através da reação de um álcool com os triglicerídeos presentes em óleos vegetais e gorduras animais. Essa reação, denominada transesterificação, produz, além do biodiesel como produto principal, o glicerol como subproduto. A reação pode ocorrer na presença de catalisadores homogêneos (ácidos ou básicos), heterogêneos (enzimáticos, básicos ou ácidos) ou também em meio supercrítico (DABDOUB e BRONZEL, 2009).

Ainda de acordo com Dabdoub e Bronzel (2009), devido a grande quantidade de variáveis que podem afetar o rendimento da produção de uma planta de biodiesel, tais como a razão molar álcool/óleo, tipo de catalisador, temperatura de operação, entre outros fatores, tem-se que softwares de simulação apresentam extrema importância para elaboração do design e avaliação de possíveis futuras plantas de biodiesel, uma vez que possibilitam a realização de um processo integrado e otimizado. Com isso uma das formas de tornar o biodiesel mais atrativo e competitivo no mercado se caracteriza pela implementação de um design aprimorado da planta de produção de biodiesel, uma vez que, isso pode levar a redução dos custos de produção.

A análise econômica de um processo também é essencial para se determinar a viabilidade de uma planta e também detectar o que causa a maior parte dos gastos nela a fim de tentar reduzi-los. Neste trabalho realizou-se uma análise econômica para os três tipos de produção de biodiesel simulados, catálise básica, ácida e em meio supercrítico para dessa forma determinar o mais viável. O principal fator de análise foi o MSP, minimum sale price, que permite relacionar o produto e seu custo de produção. 


\section{MATERIAIS E MÉTODOS}

Os procedimentos para a realização da simulação consistiram primeiro na seleção dos componentes utilizados no processo e na escolha do pacote termodinâmico adequado. Posteriormente foram inseridas as correntes de alimentação de acordo com a capacidade da planta planejada, as operações unitárias e as condições operacionais. Todos os processos tiveram por base o fluxograma da Figura 1.

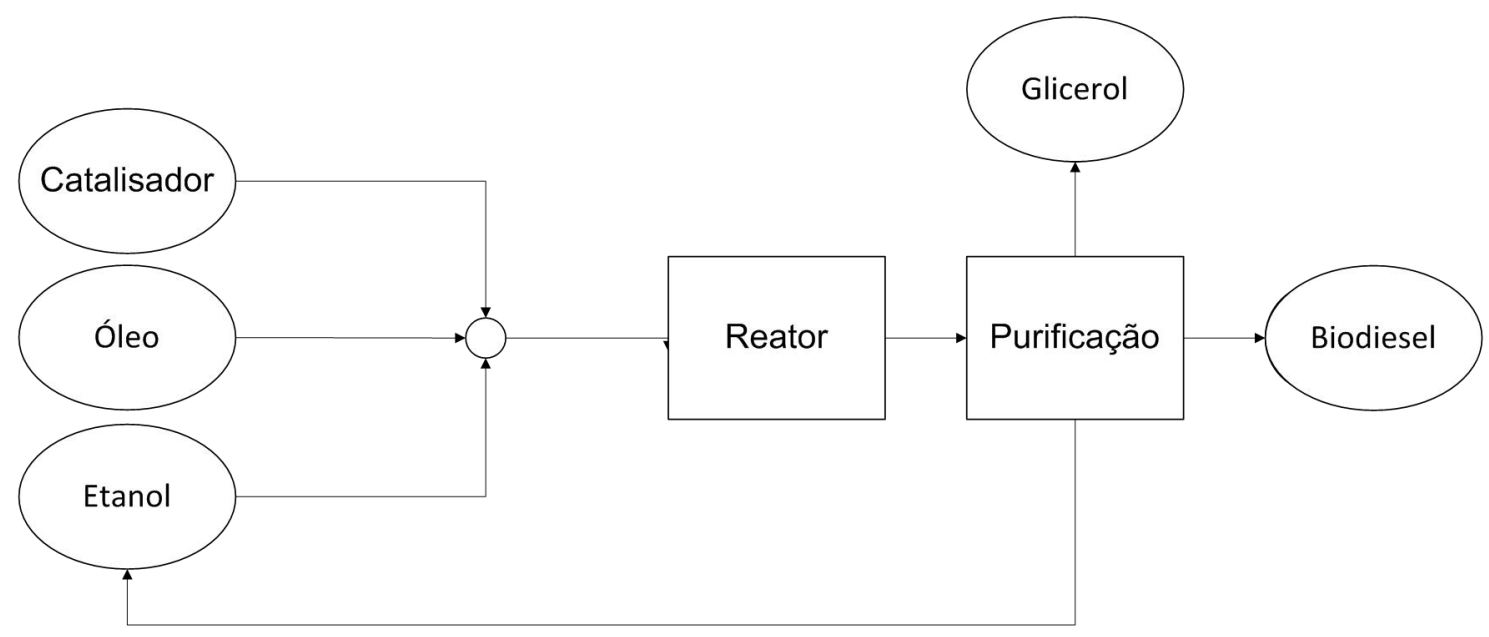

Figura 1 - Fluxograma da produção de biodiesel.

\subsection{Componentes Químicos}

De acordo com Del Río et al. (2016), trioleína e ácido oleico são respectivamente o triglicerídeo e o ácido graxo livre presentes na maior proporção no óleo de macaúba. $\mathrm{Na}$ Tabela 1 estão as frações adotadas na simulação.

Tabela 1 - Composição simpliticada adotada para o óleo de macaúba.

\begin{tabular}{llc}
\hline & Fração & Componente \\
\hline Ácido Graxo Livre & $4,93 \%$ & Ácido oleico \\
Triglicerídeo & $95,07 \%$ & Trioleína \\
\hline
\end{tabular}

O banco de dados do simulador HYSYS contêm informações sob os seguintes componentes químicos utilizados nas três simulações: água, trioleína, ácido oleico, etanol, glicerol, hidróxido de sódio e ácido sulfúrico. O oleato de etila não se encontra presente na biblioteca do software HYSYS, dessa forma inseriu-se manualmente este componente 
utilizando a ferramenta "Hypo Manager". Para a especificação de um componente foi necessário inserir certas propriedades como massa molecular, ponto de ebulição, densidade, além de propriedades críticas. Todas as propriedades inseridas encontram-se na Tabela 2.

Tabela 2 - Propriedades do oleato de etila inseridas na simulação.

\begin{tabular}{lllr}
\hline \multicolumn{2}{c}{ Propriedades } & \multicolumn{1}{c}{ Propriedades Criticas } \\
\hline Massa Molecular $\left(\mathrm{g} \mathrm{mol}^{-1}\right)$ & 310,5 & Temperatura $\left({ }^{\circ} \mathrm{C}\right)$ & 4979 \\
Ponto de Ebulição $\left({ }^{\circ} \mathrm{C}\right)$ & 206,6 & Pressão $(\mathrm{kPa})$ & 1157 \\
Densidade $\left(\mathrm{kg} \mathrm{m}^{-3}\right)$ & 870 & Volume $\left(\mathrm{m}^{3} \mathrm{kgmol}^{-1}\right)$ & 1,177 \\
& & Acentricidade & 1,013 \\
\hline
\end{tabular}

Fonte: García et al.(2010).

\subsection{Modelos Termodinâmicos}

Os modelos termodinâmicos utilizados nas simulações foram o Non-Random Two Liquid (NRTL) e o UNIversal QUAsiChemical (UNIQUAC), sendo o primeiro utilizado nas simulações onde ocorreram catálise ácida e catálise básica e o segundo na simulação em meio supercrítico. Esses modelos foram escolhidos devido à presença de compostos polares como etanol e glicerol, tornando estes pacotes os mais adequados para o cálculo do coeficiente de atividade da fase líquida. Nas simulações referentes à catálise ácida e básica, devido à presença de colunas de extração líquido-líquido, foi também necessário utilizar o método UNIFAC LLE (Universal Functional Activity Coefficient) para se estimar os parâmetros de interação binária, uma vez que estes não se encontram presentes no banco de dados do software.

\subsection{Plantas Simuladas}

Este trabalho realizou a simulação de três tipos de planta para a produção de biodiesel, uma baseada na transesterificação ocorrendo em meio supercrítico e as outras duas simulando a transesterificação com catalisadores homogêneos, no caso uma com catalisador ácido e a outra com catalisador básico (sendo necessária nesta última uma etapa de pré-tratamento com catalisador ácido para reduzir a acidez do óleo). As três simulações realizadas foram de processos contínuos e utilizaram uma vazão de entrada de $1000 \mathrm{~kg} \mathrm{~h}^{-1}$ de óleo de macaúba, sendo o etanol o álcool utilizado. Tendo em vista a ausência de dados cinéticos, foram utilizados nas simulações reatores de conversão, isto é, foi necessário apenas inserir as reações devidamente balanceadas e posteriormente inserir a conversão desejada. As simulações foram baseadas nos trabalhos de Zhang et al. (2003), West et al. (2008) e Torres (2015). 


\subsection{Produção por Catálise Ácida}

Para a planta baseada na rota de catálise homogênea ácida, utilizou-se uma razão molar álcool/óleo de 50:1 (ARANDA et al., 2008) e uma razão 1,3:1 catalisador/óleo (ZHANG et al., 2003), sendo o catalisador utilizado o ácido sulfúrico, $\mathrm{H}_{2} \mathrm{SO}_{4}$. O processo simulado consistiu da entrada do etanol e do óleo de macaúba em um reator de conversão, operando a $80^{\circ} \mathrm{C}$ (ARANDA et al., 2007). A conversão da reação utilizada foi de $97 \%$, de acordo com os dados encontrados experimentalmente por Aranda et al., (2007). Enviou-se a corrente de saída do reator para uma coluna de destilação com o objetivo de separar e recuperar o etanol não reagido para reciclá-lo no processo. A corrente principal, contendo biodiesel e componentes não reagidos, como catalisador e óleo, foi então encaminhada para outro reator com o intuito de neutralizar o ácido, usando-se para isso o óxido de cálcio. $\mathrm{O}$ sulfato de cálcio sólido formado foi então separado em um SPLITTER, este é um componente do simulador usado quando um processo de separação real não está presente, nesse caso seria um decantador. A corrente de biodiesel foi encaminhada para etapa de purificação, realizada através de uma lavagem com água. $O$ biodiesel foi obtido com a pureza desejada e a corrente restante foi encaminhada para outra coluna de destilação para separar o glicerol dos demais componentes.

\subsection{Produção por Catálise Básica}

\subsubsection{Etapa de Pré-Tratamento}

Devido à presença de ácido graxos livres em quantidades elevadas, fez-se necessário a presença de uma etapa de pré tratamento com o objetivo de esterificar esses ácidos e evitar a reação de saponificação quando na presença de catalisadores básicos. Para isso utilizou-se uma razão 1:9 óleo/álcool (MACHADO, 2013) junto do catalisador, ácido sulfúrico, 2\% em massa da quantidade de óleo (MACHADO, 2013). A mistura foi encaminhada para um reator operando a $70^{\circ} \mathrm{C}$, o produto obtido foi então direcionado a um extrator líquido-líquido para ser lavado com glicerina. Removeu-se assim o ácido sulfúrico não reagido e também a água formada na reação de esterificação. $O$ óleo tratado junto com biodiesel produzido foi encaminhado para a unidade de transesterificação alcalina e a corrente contendo etanol para uma coluna de destilação visando à purificação deste, tornando possível o seu reciclo no processo.

\subsubsection{Etapa de Transesterificação Alcalina}

O óleo já tratado, proveniente da etapa de pré-tratamento ácido, etanol com vazão molar 6:1 em relação ao óleo (WEST et al, 2007) e catalisador hidróxido de sódio, $\mathrm{NaOH}$, $1,5 \%$ em massa de óleo (WEST et al, 2007) foram encaminhados à um reator operando a $60^{\circ} \mathrm{C}$. Enviou-se a corrente de saída do reator à coluna de destilação, o etanol destilado foi reciclado e a corrente de fundo direcionada a um extrator líquido-líquido onde ocorreu a lavagem com água. A corrente de topo do extrator continha biodiesel com pureza superior a exigida. Encaminharam-se os outros produtos a um reator para neutralização do catalisador 
não reagido, para isso utilizou-se o ácido fosfórico, $\mathrm{H}_{3} \mathrm{PO}_{4}$, formando-se na reação fosfato de sódio, $\mathrm{Na}_{3} \mathrm{PO}_{4}$, subproduto que tem aplicação na indústria de fertilizantes. O fosfato de sódio foi separado e o glicerol, juntamente com os demais resíduos, foi encaminhado à outra coluna de destilação para sua purificação.

\subsection{Rota Supercrítica}

Para a produção de biodiesel em meio supercrítico usou-se a razão molar etanol/óleo 40:1. Com essa razão Choi et al. (2011), Velez et al. (2012) e Vieitez et al. (2012) obtiveram as melhores taxas de conversão em seus experimentos. A mistura reacional contendo o óleo e o etanol foi enviada ao reator operando a $330{ }^{\circ} \mathrm{C}$ e $20 \mathrm{MPa}$ (GIRARDI, 2015). Para a separação dos produtos da reação foram usadas duas colunas de destilação, na primeira separou-se o etanol, que foi reciclado, dos demais produtos, já na segunda obteve-se o biodiesel no topo da coluna e a glicerina como produto de fundo.

\subsection{Análise Econômica}

Tendo em vista que nos três processos obteve-se biodiesel com as especificações necessárias, realizou-se uma análise econômica para cada um dos casos. Os dados necessários para as análises foram obtidos utilizando a ferramenta "Economic Evaluation" do software Aspen HYSYS 8.8. Essa ferramenta forneceu informações importantes para a análise de investimentos, como o custo total do capital, o custo operacional da planta, o custo dos equipamentos, gastos com utilidades entre outros. Esses dados foram gerados a partir do mapeamento da planta simulada através do dimensionamento dos equipamentos de cada operação unitária, permitindo a obtenção de um resultado condizente com a realidade. Os preços das matérias-primas utilizadas e dos produtos obtidos também foram inseridos no simulador para a avaliação dos custos e do rendimento das operações. A Tabela 3 contém os valores de cada matéria-prima utilizada.

Tabela 3- Preços das matérias primas empregadas e dos produtos obtidos nas simulações.

\begin{tabular}{|c|c|c|c|c|c|}
\hline Matéria Prima & $\begin{array}{c}\text { Preço } \\
\left(\mathrm{US} \$ \mathrm{~kg}^{-1}\right)\end{array}$ & Matéria Prima & $\begin{array}{c}\text { Preço } \\
\left(\mathrm{US} \$ \mathrm{~kg}^{-1}\right)\end{array}$ & Produtos & $\begin{array}{c}\text { Preço } \\
\left(\mathrm{US} \$ \mathrm{~kg}^{-1}\right)\end{array}$ \\
\hline Óleo de Macaúbab & 0,70 & $\mathrm{NaOH}^{\mathrm{a}}$ & 0,51 & Biodiesel $^{\mathrm{a}}$ & 0,96 \\
\hline Etanol $^{c}$ & 0,844 & $\mathrm{CaO}^{\mathrm{a}}$ & 0,14 & Glicerol $^{\mathrm{a}}$ & 0,79 \\
\hline $\mathrm{H}_{2} \mathrm{SO}_{4}{ }^{\mathrm{a}}$ & 0,20 & $\mathrm{H}_{3} \mathrm{PO}_{4}^{\mathrm{a}}$ & 0,83 & $\mathrm{CaSO}_{4}^{\mathrm{a}}$ & 0,95 \\
\hline Glicerol $^{\mathrm{a}}$ & 0,79 & Água ${ }^{a}$ & 0,00005 & $\mathrm{Na}_{3} \mathrm{PO}_{4}{ }^{\mathrm{a}}$ & 1,77 \\
\hline
\end{tabular}

Fonte: Albuquerque (2015) ${ }^{\mathrm{a}}$, Diaz et al $(2013)^{\mathrm{b}}$, ESALQ (2016) 
A ferramenta "Investment Analisys", também oferecida pelo software, foi capaz de gerar a partir das informações anteriores uma análise mais detalhada. Com ela obteve-se valores estimados de diversos tipos de custos, como mão de obra, instalação, design, engenharia, entre outros.

\subsection{Análise de Fluxo de Caixa}

O preço mínimo de venda (MSP) é o preço mais baixo que o produto pode ser oferecido no mercado levando o lucro à zero. Para calcular o MSP realiza-se uma análise de fluxo de caixa descontado, sendo necessário o custo capital total, o custo total de operação anualizado, a produção total de biodiesel e o fator de recuperação de capital (CRF). A Equação (1) representa o cálculo do CRF e a Equação (2) o cálculo do MSP.

$\mathrm{CRF}=\mathrm{i} * \frac{(1+\mathrm{i})^{\mathrm{n}}}{\left[(1+\mathrm{i})^{\mathrm{n}}-1\right]}$

MSP $=\frac{\text { (CRF X Custo de Investimento Total +Custo de Operaçâo) }}{\text { Produçẫo Total de Biodiesel }}$

Na Equação (1) o termo "n" representa o tempo de vida da planta e o termo "i” é a taxa de retorno desejada. Para as três simulações adotou-se o tempo de vida da planta como 20 anos e a taxa de retorno desejada equivalente à $20 \%$. Entre as considerações realizadas estavam que a planta opera de forma contínua em estado estacionário durante 8760 horas por ano.

\subsection{Análise Paramétrica}

A análise de sensibilidade é realizada com o objetivo de observar o efeito da variação de certos parâmetros na produção e dessa forma obter novos resultados econômicos, com isso obtendo-se novos valores de MSP. Para as três simulações variou-se a vazão de óleo de macaúba na entrada e também o seu preço, sendo a variação do primeiro de $30 \%$, para mais e para menos e a variação do segundo de $25 \%$ da mesma forma. Nos casos onde ocorreu a variação da entrada de óleo também se foi necessário o ajuste da entrada de etanol para que a estequiometria de cada processo continuasse a ser respeitada. Uma nova análise econômica foi realizada para esses casos e o novo MSP calculado. 


\section{RESULTADOS E DISCUSSÃO}

\subsection{Processo Supercrítico}

O diagrama de fluxo de processo, $\mathrm{PFD}$, da planta de produção de biodiesel pela rota supercrítica está na Figura 2 e na Tabela 4 as informações da principais correntes dos processo.

\subsubsection{Transesterificação}

A corrente 103, formada pela mistura entre o etanol adicionado ao processo e a corrente de reciclo $(99,12 \%$ em massa de etanol), foi misturada a corrente contendo o óleo, e logo depois bombeada e pré-aquecida antes de ser enviada ao reator. A conversão adotada para a reação foi de $95,9 \%$ (TORRES, 2015).

\subsubsection{Recuperação do Etanol}

Após a reação, a corrente 107 trocou calor com a corrente 106 no trocador E-100 e passou pela válvula VLV-100, onde sua pressão caiu de $20 \mathrm{MPa}$ para 101,3 kPa. Em seguida ela foi enviada para a torre de destilação T-100 para recuperação do etanol. Nessa torre, usando-se sete pratos e um taxa de refluxo de 2,0, foi possível recuperar $85,37 \%$ do etanol como produto de topo, que foi resfriado e reciclado de volta ao processo. A corrente de fundo continha majoritariamente biodiesel e glicerol.

\subsubsection{Recuperação do Biodiesel}

A corrente de fundo da coluna T-100 (111) foi enviada a torre T-101 para separação do biodiesel do glicerol. Usando-se cinco pratos e uma taxa de refluxo de dois quase todo o biodiesel foi recuperado como produto de topo $(99,99 \%)$, com uma fração mássica de $99,91 \%$, superior às especificações exigidas. O glicerol saiu como produto de fundo na coluna, 99,47\% foi recuperado com uma fração mássica de $65,34 \%$.

\subsection{Processo Alcalino}

O diagrama de fluxo de processo, $\mathrm{PFD}$, da planta de produção de biodiesel pela rota catalítica homogênea básica estão nas Figuras 3 e 4 e os balanços de massa e energia nas Tabelas 5 e 6 . 


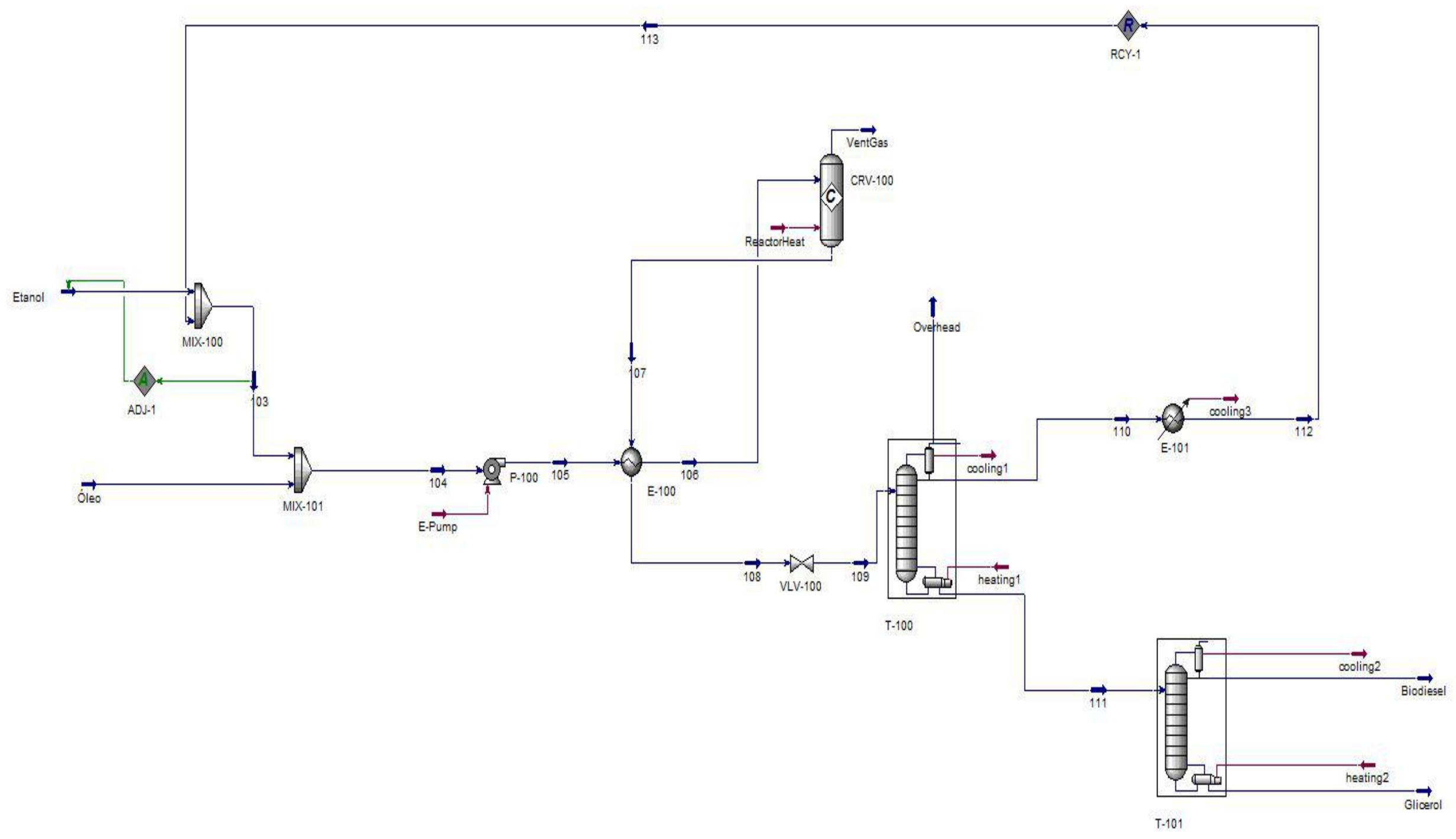

Figura 2 - PFD da planta operando pela rota supercrítica. 
Tabela 4 - Balanço de massa e energia da planta supercrítica.

\begin{tabular}{|c|c|c|c|c|c|c|c|c|c|c|c|}
\hline \multicolumn{12}{|c|}{ SUPERCRÍTICO } \\
\hline Corrente & Etanol & Óleo & 103 & 105 & 106 & 107 & 109 & 110 & 111 & Biodiesel & Glicerol \\
\hline Temperatura $\left[{ }^{\circ} \mathrm{C}\right]$ & 25,0 & 25,0 & 25,0 & 37,64 & 320 & 330 & 82,11 & 78,11 & 228,01 & 70,20 & 227,87 \\
\hline Pressão $[\mathrm{kPa}]$ & 101,32 & 101,32 & 101,3 & 20000 & 20000 & 20000 & 101,3 & 101,3 & 105,4 & 10,0 & 15,0 \\
\hline Vazão Molar [kgmole h ${ }^{-1}$ ] & 9,97 & 1,25 & 50,24 & 51,49 & 51,49 & 51,49 & 51,49 & 40,27 & 4,32 & 3,24 & 1,08 \\
\hline Vazão Mássica $\left[\mathrm{kg} \mathrm{h}^{-1}\right]$ & 459,42 & 1000 & 2289,42 & 3289,42 & 3289,42 & 3289,36 & 3289,36 & 1830 & 1146 & 1003,00 & 143,00 \\
\hline Vazão Volumétrica $\left[\mathrm{m}^{3} \mathrm{~h}^{-1}\right]$ & 0,58 & 1,09 & 2,87 & 3,97 & 3,97 & 3,97 & 3,97 & 2,29 & 1,29 & 1,15 & 0,13 \\
\hline Fluxo de Calor $\left[10^{6} \mathrm{~kJ} \mathrm{~h}^{-1}\right]$ & 2,8 & 2,3 & 14,0 & 16,0 & 14,0 & 13,0 & 15,0 & 11,0 & 2,4 & 2,0 & 0,74 \\
\hline \multicolumn{12}{|l|}{ Fração Mássica } \\
\hline Ácido Oleico & 0,00 & 0,05 & 0,00 & 0,02 & 0,02 & 0,00 & 0,00 & 0,00 & 0,00 & 0,00 & 0,01 \\
\hline Trioleína & 0,00 & 0,95 & 0,00 & 0,29 & 0,29 & 0,01 & 0,01 & 0,00 & 0,04 & 0,00 & 0,33 \\
\hline Glicerol & 0,00 & 0,00 & 0,00 & 0,00 & 0,00 & 0,03 & 0,03 & 0,00 & 0,08 & 0,00 & 0,65 \\
\hline Etanol & 1,00 & 0,00 & 0,99 & 0,69 & 0,69 & 0,65 & 0,65 & 0,99 & 0,00 & 0,00 & 0,00 \\
\hline Água & 0,00 & 0,00 & 0,01 & 0,00 & 0,00 & 0,01 & 0,01 & 0,01 & 0,00 & 0,00 & 0,00 \\
\hline Oleato de Etila & 0,00 & 0,00 & 0,00 & 0,00 & 0,00 & 0,30 & 0,30 & 0,00 & 0,87 & 1,00 & 0,00 \\
\hline
\end{tabular}




\subsubsection{Pré Tratamento}

\subsubsection{Esterificação}

Duas correntes foram enviadas ao reator, uma formada pela mistura de etanol reciclado, etanol adicionado ao processo e ácido sulfúrico (corrente 102). A segunda continha o óleo previamente aquecido pela troca de calor com a corrente de saída do reator (corrente 105B). No reator considerou-se uma conversão de 100\% dos ácidos graxos livres.

\subsubsection{Lavagem com Glicerina}

Antes de o óleo ser enviado para a transesterificação ele foi separado da água formada na reação de esterificação e do excesso de ácido que não reagiu. Para isso a corrente de saída do reator (107) foi enviada a um extrator líquido-líquido (T-100). Usou-se para a lavagem uma corrente de glicerol de $110 \mathrm{~kg} \mathrm{~h}^{-1}$ e três estágios teóricos na coluna. O produto de topo obtido continha apenas biodiesel e glicerol (corrente 108), enquanto toda a água e o ácido saíram no produto de fundo (corrente 109).

\subsubsection{Recuperação do Etanol}

Para a recuperação do etanol a corrente $110 \mathrm{~B}$ foi enviada a coluna de destilação T101. Nela usando-se cinco estágios teóricos e uma razão de refluxo de cinco foi possível recuperar $82,59 \%$ do etanol como corrente de topo (111). Essa corrente foi reciclada para o começo do processo.

\subsubsection{Etapa de Transesterificação}

\subsubsection{Transesterificação}

O óleo pré-tratado na etapa anterior foi enviado ao reator para a reação de transesterificação, juntamente com a corrente formada por etanol adicionado ao processo, etanol reciclado e o catalisador alcalino. No reator a conversão adotada foi de $98 \%$.

\subsubsection{Recuperação do Etanol}

A corrente de saída do reator foi enviada a coluna de destilação T-100 para recuperação do etanol. Utilizando-se seis estágios teóricos e uma razão de refluxo de dois foi possível recuperar 95,91\% de etanol como corrente de topo (corrente 201) e uma corrente de fundo contendo majoritariamente biodiesel e glicerol (corrente 202). 


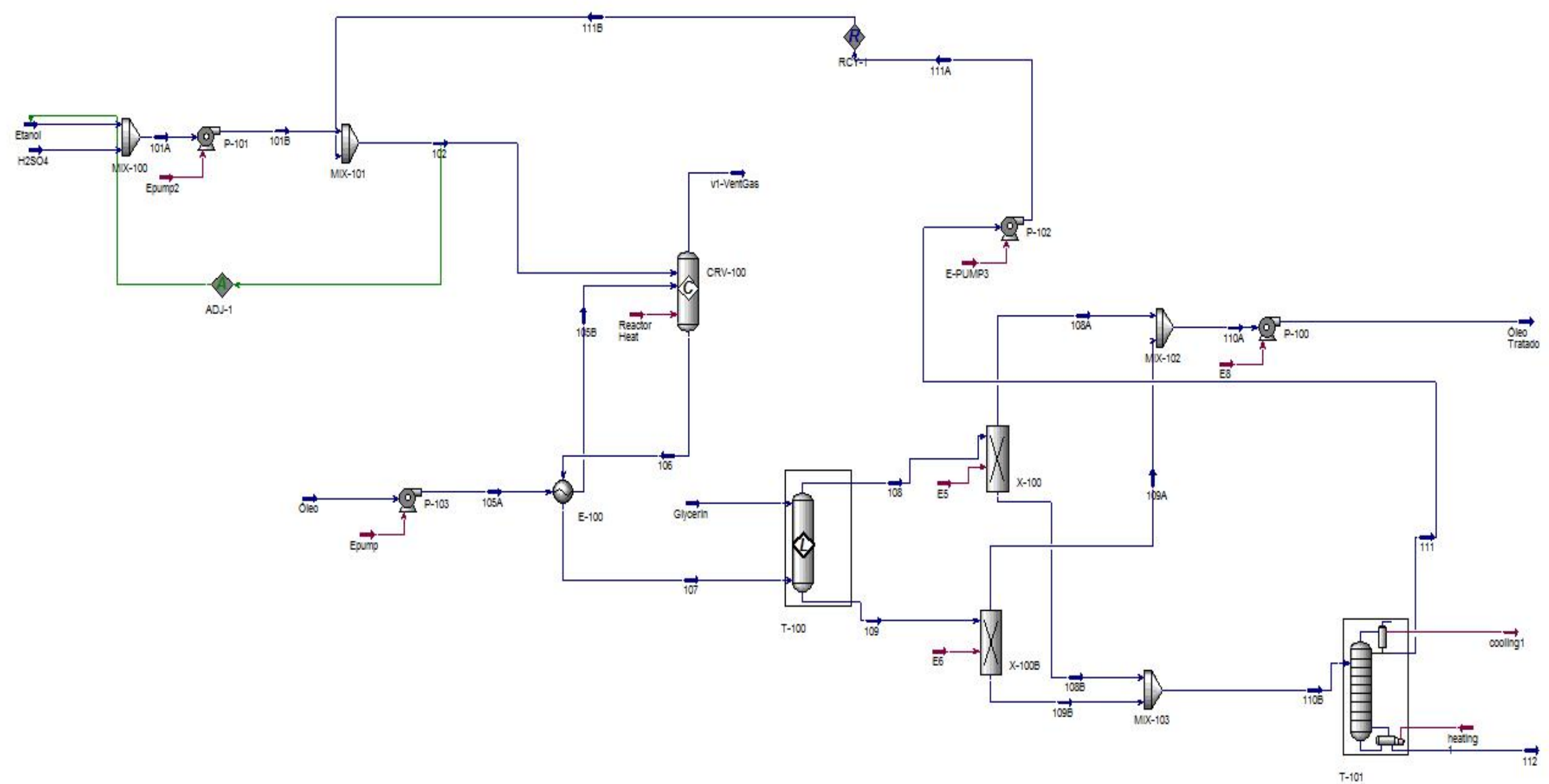

Figura 3- PFD da etapa de pré-tratamento da planta de catálise básica. 
Tabela 5- Balanço de massa e energia da etapa de pré tratamento da planta de catálise básica.

\begin{tabular}{|c|c|c|c|c|c|c|c|c|c|c|c|c|c|c|}
\hline & & & & RE-TR & TAMEI & NTO D & I CATALI & SE BAs & ICA & & & & & \\
\hline Corrente & Etanol & $\mathrm{H}_{2} \mathrm{SO}_{4}$ & Óleo & 102 & $105 \mathrm{~B}$ & 106 & Glicerina & 108 & 109 & $110 \mathrm{~A}$ & 110B & 111 & 112 & $\begin{array}{c}\text { Óleo } \\
\text { Tratado }\end{array}$ \\
\hline Temperatura $[\mathrm{C}]$ & 25,0 & 25,0 & 25,0 & 38,9 & 65,0 & 70,0 & 25,0 & 30,6 & 64,11 & 50,0 & 28,0 & 42,2 & 60,2 & 50,91 \\
\hline Pressão [kPa] & 101,3 & 101,3 & 101,3 & 400,0 & 400,0 & 400,0 & 200,0 & 200,0 & 400,0 & 190,0 & 20,0 & 20,0 & 30,0 & 400,0 \\
\hline $\begin{array}{l}\text { Vazão Molar } \\
{\left[\text { kgmole } h^{-1}\right]}\end{array}$ & 2,17 & 0,20 & 1,25 & 12,05 & 1,25 & 13,30 & 1,19 & 0,73 & 13,76 & 1,25 & 13,24 & 9,67 & 3,57 & 1,25 \\
\hline $\begin{array}{l}\text { Vazão Mássica [kg } \\
\left.\mathrm{h}^{-1}\right]\end{array}$ & 100,0 & 20,0 & 1000,0 & 560,00 & 1000,0 & 1559 & 110,0 & 103,3 & 1566,7 & 1004,8 & 665,1 & 440,0 & 225,1 & 1004,9 \\
\hline $\begin{array}{l}\text { Vazão Volumétrica } \\
{\left[\mathrm{m}^{3} \mathrm{~h}^{-1}\right]}\end{array}$ & 0,13 & 0,011 & 1,1 & 0,69 & 1,09 & 1,78 & 0,087 & 0,10 & 1,77 & 1,10 & 0,77 & 0,55 & 0,22 & 1,10 \\
\hline $\begin{array}{l}\text { Fluxo de Calor }\left[10^{6}\right. \\
\left.\mathrm{kJ} \mathrm{h}^{-1}\right] \\
\text { Fração Mássica }\end{array}$ & 60,0 & 16,0 & 2,3 & 3,4 & 2,2 & 5,6 & 81,0 & 49,0 & 5,9 & 2,2 & 4,3 & 2,7 & 1,6 & 2,2 \\
\hline Etanol & 1,00 & 0,00 & 0,00 & 0,96 & 0,00 & 0,34 & 0,00 & 0,00 & 0,34 & 0,00 & 0,79 & 0,99 & 0,41 & 0,00 \\
\hline Trioleína & 0,00 & 0,00 & 0,95 & 0,00 & 0,95 & 0,61 & 0,00 & 0,00 & 0,61 & 0,95 & 0,00 & 0,00 & 0,00 & 0,95 \\
\hline Ácido Oleico & 0,00 & 0,00 & 0,05 & 0,00 & 0,05 & 0,00 & 0,00 & 0,00 & 0,00 & 0,00 & 0,00 & 0,00 & 0,00 & 0,00 \\
\hline Ácido Sulfúrico & 0,00 & 1,00 & 0,00 & 0,04 & 0,00 & 0,01 & 0,00 & 0,00 & 0,01 & 0,00 & 0,03 & 0,00 & 0,09 & 0,00 \\
\hline $\mathrm{NaOH}$ & 0,00 & 0,00 & 0,00 & 0,00 & 0,00 & 0,00 & 0,00 & 0,00 & 0,00 & 0,00 & 0,00 & 0,00 & 0,00 & 0,00 \\
\hline Água & 0,00 & 0,00 & 0,00 & 0,01 & 0,00 & 0,00 & 0,00 & 0,00 & 0,00 & 0,00 & 0,01 & 0,01 & 0,01 & 0,00 \\
\hline Oleato de Etila & 0,00 & 0,00 & 0,00 & 0,00 & 0,00 & 0,03 & 0,00 & 0,49 & 0,00 & 0,05 & 0,00 & 0,00 & 0,00 & 0,05 \\
\hline Glicerol & 0,00 & 0,00 & 0,00 & 0,00 & 0,00 & 0,00 & 1,00 & 0,50 & 0,04 & 0,00 & 0,17 & 0,00 & 0,49 & 0,00 \\
\hline
\end{tabular}




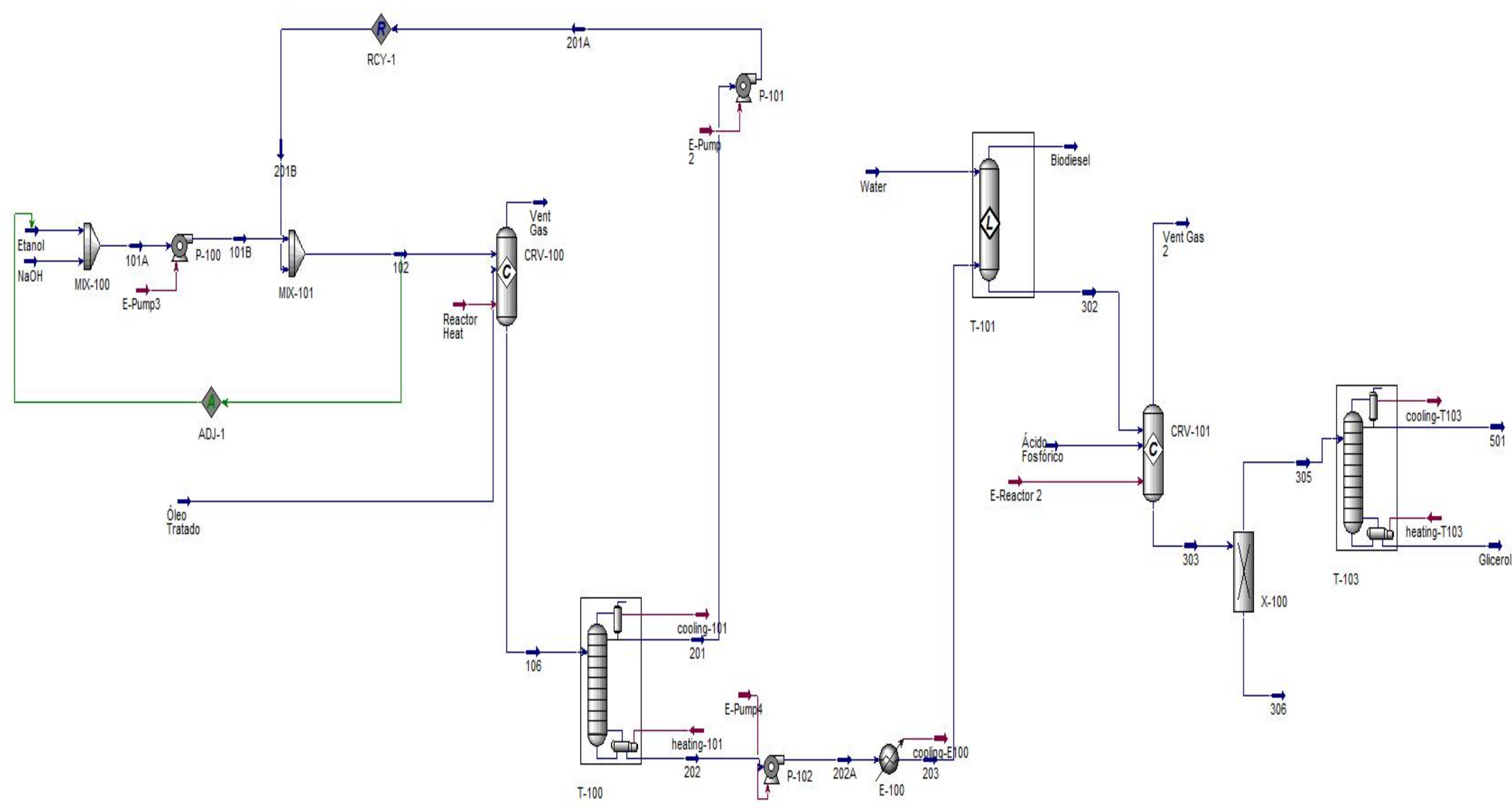

Figura 4 - PFD da planta de catálise básica. 
Tabela 6 - Balanço de massa e energia da planta de transesterificação da planta de catálise básica.

\begin{tabular}{|c|c|c|c|c|c|c|c|c|c|c|c|c|c|c|c|c|}
\hline \multicolumn{17}{|c|}{ TRANSESTERIFICAÇÃO BÁSICA } \\
\hline Corrente & $\begin{array}{l}\text { Óleo } \\
\text { Tratado }\end{array}$ & Etanol & $\mathrm{NaOH}$ & 101B & 102 & 106 & 202 & Água & Biodiesel & 302 & $\begin{array}{c}\text { Ácido } \\
\text { Fosfórico }\end{array}$ & 303 & 305 & 306 & 501 & Glicerol \\
\hline Temperatura $\left[{ }^{\circ} \mathrm{C}\right]$ & 50,9 & 25,0 & 25,0 & 25,2 & 34,40 & 60,0 & 114,6 & 25,0 & 28,3 & 43,72 & 25,0 & 60,0 & 60,0 & 60,0 & 74,15 & 263,9 \\
\hline Pressão [kPa] & 400,0 & 101,3 & 101,3 & 400,0 & 400,0 & 400,0 & 30,0 & 101,3 & 110,0 & 120,0 & 101,3 & 101 & 110,0 & 110,0 & 40,0 & 50,0 \\
\hline Vazão Molar [kgmole h-1 ${ }^{-1}$ & 1,25 & 3,3 & 0,38 & 3,7 & 7,9 & 9,1 & 4,9 & 26,4 & 3,3 & 28,1 & 0,13 & 28,2 & 28,1 & 0,13 & 27,1 & 1,1 \\
\hline $\begin{array}{l}\text { Vazão Mássica } \\
{\left[\mathrm{kg} \mathrm{h}^{-1}\right]}\end{array}$ & 1005,0 & 153,5 & 15,07 & 168,6 & 368,6 & 1373 & 1173 & 475,0 & 1007 & 641,1 & 12,4 & 653 & 632,8 & 20,7 & 518,5 & 114,3 \\
\hline $\begin{array}{l}\text { Vazão Volumétrica }\left[\mathrm{m}^{3} \mathrm{~h}^{-}\right. \\
\left.{ }^{1}\right]\end{array}$ & 1,1 & 0,19 & 0,0085 & 0,20 & 0,45 & 1,56 & 1,31 & 0,48 & 1,16 & 0,62 & 0,0067 & 0,63 & 0,62 & 0,0087 & 0,53 & 0,009 \\
\hline Fluxo de calor $\left[10^{6} \mathrm{~kJ} . \mathrm{h}^{-1}\right]$ & 2,2 & 93,0 & 310 & 96,0 & 2,1 & 400,0 & 2,8 & 7,5 & 2,1 & 8,4 & 0,015 & 9,5 & 8,4 & 1,1 & 7,6 & 69,0 \\
\hline \multicolumn{17}{|l|}{ Fração Mássica } \\
\hline Etanol & 0,00 & 1,00 & 0,00 & 0,91 & 0,93 & 0,14 & 0,01 & 0,00 & 0,00 & 0,01 & 0,00 & 0,01 & 0,01 & 0,00 & 0,02 & 0,00 \\
\hline Trioleína & 0,95 & 0,00 & 0,00 & 0,00 & 0,00 & 0,01 & 0,02 & 0,00 & 0,00 & 0,03 & 0,00 & 0,03 & 0,03 & 0,00 & 0,00 & 0,15 \\
\hline Oleato de Etila & 0,05 & 0,00 & 0,00 & 0,00 & 0,03 & 0,76 & 0,88 & 0,00 & 1,00 & 0,05 & 0,00 & 0,04 & 0,05 & 0,00 & 0,06 & 0,00 \\
\hline Glicerol & 0,00 & 0,00 & 0,00 & 0,00 & 0,00 & 0,07 & 0,08 & 0,00 & 0,00 & 0,15 & 0,00 & 0,15 & 0,15 & 0,00 & 0,00 & 0,85 \\
\hline Água & 0,00 & 0,00 & 0,00 & 0,00 & 0,00 & 0,00 & 0,00 & 1,00 & 0,00 & 0,74 & 0,00 & 0,74 & 0,76 & 0,00 & 0,93 & 0,00 \\
\hline $\mathrm{NaOH}$ & 0,00 & 0,00 & 1,00 & 0,09 & 0,04 & 0,01 & 0,01 & 0,00 & 0,00 & 0,02 & 0,00 & 0,00 & 0,00 & 0,00 & 0,00 & 0,00 \\
\hline Ácido Fosfórico & 0,00 & 0,00 & 0,00 & 0,00 & 0,00 & 0,00 & 0,00 & 0,00 & 0,00 & 0,00 & 1,00 & 0,00 & 0,00 & 0,00 & 0,00 & 0,00 \\
\hline Fosfato de Sódio & 0,00 & 0,00 & 0,00 & 0,00 & 0,00 & 0,00 & 0,00 & 0,00 & 0,00 & 0,00 & 0,00 & 0,03 & 0,00 & 1,00 & 0,00 & 0,00 \\
\hline
\end{tabular}




\subsection{Planta de Catálise Ácida}

O PFD da planta de produção de biodiesel pela rota catalítica homogênea ácida está na Figura 5, já seu seu balanço de massa e energia encontra-se na tabela 7.

\subsubsection{Reação}

A corrente 102, formada pela mistura das correntes contendo etanol adicionado ao processo, etanol reciclado e ácido sulfúrico foi enviada ao reator juntamente com a corrente de óleo, esta pré aquecida no trocador de calor E-100. No reator foi adotada a conversão de $97 \%$ para a transesterificação da trioleína e de $100 \%$ para a esterificação dos ácidos graxos livres.

\subsubsection{Recuperação do Etanol}

Uma vez que a quantidade teórica de etanol requerida (3:1 etanol/óleo) é muito inferior a quantidade utilizada (50:1), tem-se que após a etapa de reação há uma grande quantidade de etanol não reagido, sendo de fundamental importância seu reciclo para a redução dos custos operacionais. Utilizou-se uma coluna de destilação (T-100) para separar esse etanol e enviá-lo para o reciclo. A coluna foi projetada para operar com cinco estágios e uma taxa de refluxo de dois. Com essas configurações foi possível recuperar $93,83 \%$ do etanol não reagido, com uma pureza de $99,02 \%$. O aumento da taxa de refluxo e do número de estágios da coluna não se mostrou eficiente, tanto para aumentar a pureza quanto para aumentar a recuperação de etanol.

\subsubsection{Purificação do Biodiesel}

A corrente de fundo da coluna T-100 foi enviada a ao reator CRV-101 para neutralização do ácido sulfúrico. Usando-se uma corrente de óxido de cálcio, todo o ácido foi neutralizado e formou-se o produto sólido sulfato de cálcio, separado como corrente de fundo em X-100. A corrente de topo (203C) contendo biodiesel, glicerol e componentes não reagidos foi encaminhada a um extrator líquido-líquido onde o biodiesel foi purificado. $\mathrm{O}$ extrator operou com quatro estágios e a lavagem foi feita com água. A corrente contendo biodiesel foi alimentada na parte inferior e água com uma vazão de $475 \mathrm{~kg} \cdot \mathrm{h}^{-1}$ entrou pela parte superior. O biodiesel purificado sai como líquido de topo com 99,81\% de pureza em massa, atendendo dessa forma não só as exigências da Agência Nacional de Petróleo, que estipula 96,5\% de pureza, como também da ASTM que exige 99,65\%. Além disso, conseguiu-se uma recuperação de $97.99 \%$ do biodiesel, alcançando uma produção de $1003,84 \mathrm{~kg} \cdot \mathrm{h}^{-1}$ ou de 8799,63 toneladas por ano. A corrente de fundo (302) segue então para a etapa de purificação do glicerol. 


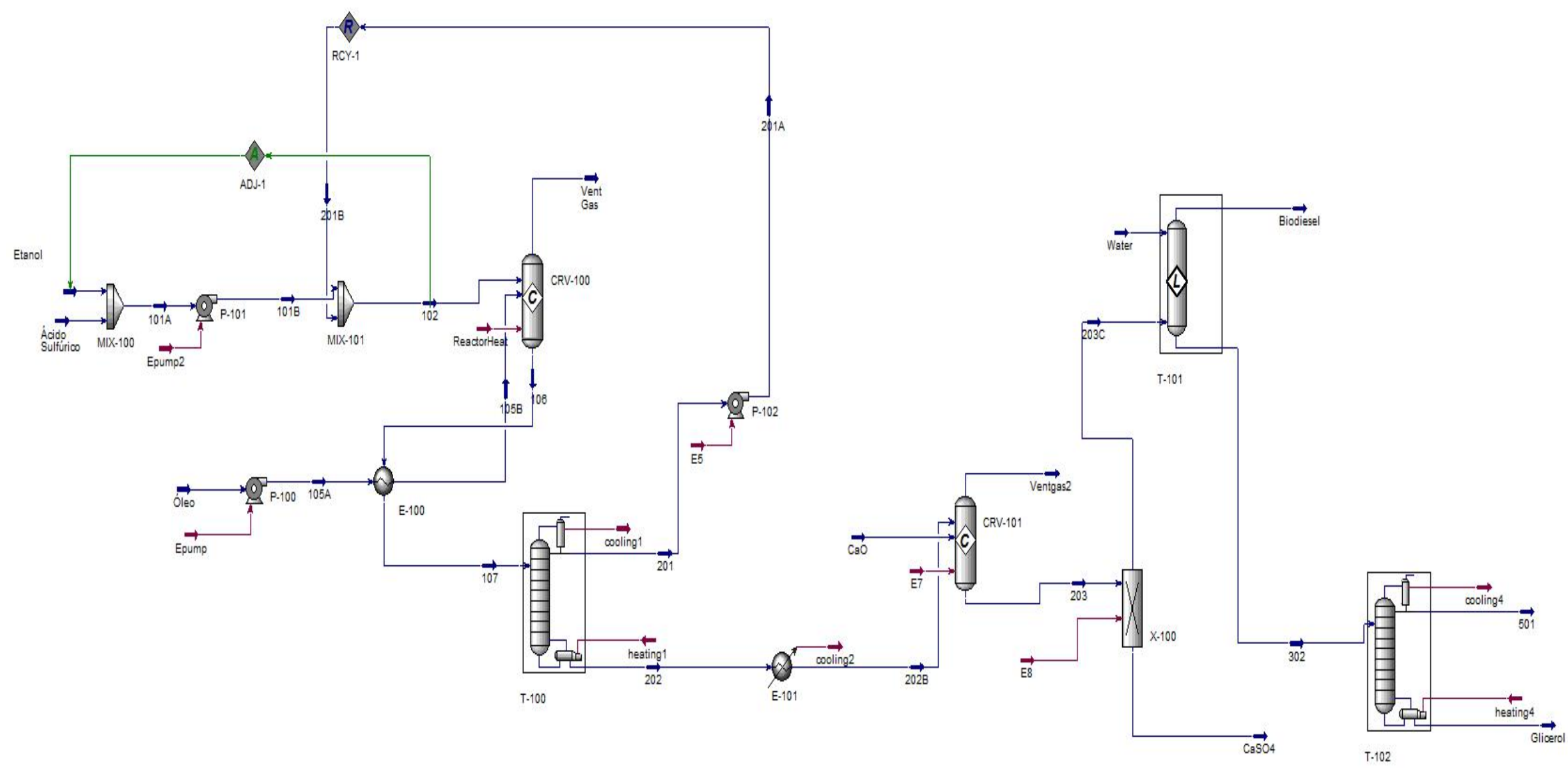

Figura 5. PFD da Planta de Catálise Acida. 
Tabela 7 - Balanço de massa e energia da planta de catálise ácida.

\begin{tabular}{|c|c|c|c|c|c|c|c|c|c|c|c|c|c|c|}
\hline \multicolumn{15}{|c|}{ CATÁLISE ÁCIDA } \\
\hline Corrente & Etanol & Óleo & $\begin{array}{l}\text { Ácido } \\
\text { Sulfúrico }\end{array}$ & 102 & $105 \mathrm{~B}$ & 106 & 201 & 203 & $203 \mathrm{C}$ & $\mathrm{CaSO}_{4}$ & 302 & 501 & Glicerol & Biodiesel \\
\hline Temperatura $\left[{ }^{\circ} \mathrm{C}\right]$ & 25,0 & 25,0 & 25,0 & 86,4 & 75,0 & 80,0 & 94,9 & 60,0 & 50,0 & 60,0 & 44,9 & 62,6 & 264,2 & 28,4 \\
\hline Pressão [kPa] & 101,3 & 101,3 & 101,3 & 400,0 & 400,0 & 400,0 & 190,0 & 200,0 & 110,0 & 130,0 & 120,0 & 40,0 & 50,0 & 110,0 \\
\hline Vazão Molar [kgmole h ${ }^{-1}$ ] & 6,9 & 1,3 & 1,6 & 64,5 & 1,3 & 65,7 & 56,0 & 11,4 & 9,7 & 1,6 & 32,9 & 31,8 & 1,1 & 3,2 \\
\hline $\begin{array}{l}\text { Vazão Mássica } \\
{\left[\mathrm{kg} \mathrm{h}^{-1}\right]}\end{array}$ & 315,8 & 1000,0 & 159,1 & 3018,2 & 1000,0 & 4018,2 & 2542,2 & 1566,9 & 1346,1 & 220,9 & 815,4 & 692,5 & 122,9 & 1005,7 \\
\hline Vazão Volumétrica $\left[\mathrm{m}^{3} \mathrm{~h}^{-1}\right]$ & 0,4 & 1,1 & 0,086 & 3,7 & 1,1 & 4,8 & 3,2 & 1,6 & 1,5 & 0,09 & 0,84 & 0,74 & 0,11 & 1,2 \\
\hline Heat Flow $\left[10^{6} \mathrm{~kJ} \mathrm{~h}^{-1}\right]$ & 1,9 & 2,25 & $-1,30$ & 18,2 & 2,24 & 20,2 & 15,0 & 4,26 & 4,3 & 0,0323 & 9,76 & 8,95 & 0,69 & 2,1 \\
\hline \multicolumn{15}{|l|}{ Fração Mássica } \\
\hline Etanol & 1,00 & 0,00 & 0,00 & 0,94 & 0,00 & 0,67 & 0,99 & 0,11 & 0,12 & 0,00 & 0,20 & 0,24 & 0,00 & 0,000 \\
\hline Ácido Oleico & 0,00 & 0,05 & 0,00 & 0,00 & 0,05 & 0,00 & 0,00 & 0,00 & 0,00 & 0,00 & 0,00 & 0,00 & 0,00 & 0,000 \\
\hline Glicerol & 0,00 & 0,00 & 0,00 & 0,00 & 0,00 & 0,02 & 0,00 & 0,06 & 0,07 & 0,00 & 0,12 & 0,00 & 0,78 & 0,000 \\
\hline Água & 0,00 & 0,00 & 0,00 & 0,01 & 0,00 & 0,01 & 0,01 & 0,02 & 0,02 & 0,00 & 0,62 & 0,73 & 0,00 & 0,000 \\
\hline Trioleína & 0,00 & 0,95 & 0,00 & 0,00 & 0,95 & 0,01 & 0,00 & 0,02 & 0,02 & 0,00 & 0,03 & 0,00 & 0,22 & 0,002 \\
\hline Ácido Sulfúrico & 0,00 & 0,00 & 1,00 & 0,05 & 0,00 & 0,04 & 0,00 & 0,00 & 0,00 & 0,00 & 0,00 & 0,00 & 0,00 & 0,000 \\
\hline Oleato de Etila & 0,00 & 0,00 & 0,00 & 0,00 & 0,00 & 0,26 & 0,00 & 0,65 & 0,76 & 0,00 & 0,03 & 0,03 & 0,00 & 0,998 \\
\hline $\mathrm{CaO}$ & 0,00 & 0,00 & 0,00 & 0,00 & 0,00 & 0,00 & 0,00 & 0,00 & 0,00 & 0,00 & 0,00 & 0,00 & 0,00 & 0,000 \\
\hline Sulfato de Cálcio & 0,00 & 0,00 & 0,00 & 0,00 & 0,00 & 0,00 & 0,00 & 0,14 & 0,00 & 1,00 & 0,00 & 0,00 & 0,00 & 0,000 \\
\hline
\end{tabular}




\subsubsection{Purificação do Glicerol}

A corrente contendo glicerol, água e componentes não reagidos, tais como trioleína, ácido oleico e resquícios de etanol, foi então direcionada para uma segunda coluna de destilação, na qual ocorreu a purificação do glicerol. A coluna foi projetada para operar com quatro estágios, sob-baixas pressões e uma razão de refluxo de dois. Na corrente de topo saiu água e etanol, já na corrente de fundo é liberado o glicerol junto da trioleína e ácido oleico não reagidos. Devido à proximidade da volatilidade do glicerol com esses componentes a destilação não foi um método eficiente para separá-los, com isso obteve-se glicerol com grau de pureza de $78,04 \%$ o que o ainda caracteriza como glicerol bruto, apresentando, dessa forma, pouco valor de mercado.

\section{ANÁLISE ECONÔMICA}

\subsection{Custo de Investimento}

O custo capital total para a implementação da planta de Catálise Ácida, Catálise Básica e Supercrítica foi de US\$ 6.729.750, US\$ 10.901.290,00 e US\$ 7.014.870,00 respectivamente. Com isso tem-se que a planta operando por Catálise Ácida foi a que demandou menor investimento. A Tabela 8 mostra de maneira mais precisa como ocorreu a divisão desses custos em cada planta.

Tabela 8 - Custo de Investimento das plantas simuladas.

\begin{tabular}{lrrr}
\hline \multicolumn{1}{c}{ Elemento } & \multicolumn{3}{c}{ Custo (US Dólar) } \\
\cline { 2 - 4 } & Catálise Ácida & Catálise Básica & \multicolumn{1}{c}{ Supercrítico } \\
\hline Compra de Equipamento & $365.320,00$ & $487.450,00$ & $1.096 .900,00$ \\
Instalação de Equipamento & $11.888,80$ & $17.828,90$ & $19.431,50$ \\
Tubulação & $457.054,00$ & $632.607,00$ & $735.667,00$ \\
Pessoal & $80.773,40$ & $114.536,10$ & $68.489,80$ \\
Aço & $39.494,30$ & $50.441,10$ & $20.668,40$ \\
Instrumentação & $920.650,00$ & $1.546 .069,00$ & $720.514,00$ \\
Elétrico & $613.125,00$ & $1.182 .176,00$ & $575.217,00$ \\
Isolamento & $121.576,00$ & $129.912,30$ & $117.950,00$ \\
Pintura & $32.951,10$ & $55.071,90$ & $23.943,60$ \\
Geral e Administração & $111.439,00$ & $177.620,80$ & $132.194,00$ \\
Despesas de Contrato & $314.828,00$ & $533.617,00$ & $294.423,00$ \\
Contingências & $1.094 .850,00$ & $1.773 .507,00$ & $1.141 .240,00$ \\
Design, Engenharia e Outros & $1.941 .600,00$ & $3.220 .900,00$ & $1.507 .100,00$ \\
Material de Construção & $208.600,00$ & $335.000,00$ & $293.100,00$ \\
Construções Indiretas & $863.200,00$ & $1.369 .600,00$ & $734.600,00$ \\
Total & $7.177 .350,00$ & $11.626 .340,00$ & $7.481 .430,00$ \\
Custo Total Ajustado & $6.729 .750,00$ & $10.901 .290,00$ & $7.014 .870,00$ \\
\hline
\end{tabular}


Baseado na Tabela 8 comparou-se os custos de investimentos para as três plantas simuladas, sendo notável que a planta operando pelo processo de catálise básica necessitou do maior investimento para sua implementação, isso ocorreu porque ela é a maior das três, uma vez que possuía uma etapa exclusiva para o pré-tratamento da acidez do óleo de macaúba. Essa etapa por consequência fez com que o processo de catálise básica exigisse um maior número de equipamentos e processos de purificação, elevando consideravelmente o gasto em todos os elementos que compõem o custo de investimento, mas principalmente, nos gastos com instrumentação, parte elétrica, construções e design e engenharia. Observou-se claramente que mesmo o processo Supercrítico apresentando menor número de equipamentos, foi nele que esse item apresentou maior peso na composição do custo total, isso ocorreu porque esta planta opera a alta pressão e temperatura, demandando dessa forma equipamentos capazes de resistir a essas condições.

\subsection{Custos de Operação}

Na Tabela 9 encontra-se a distribuição dos custos anuais de operação para os três processos. Nela pode-se ver que a Catálise Ácida, mais uma vez, foi a que apresentou o menor custo de operação anual, totalizando US\$ 11.889.100,00 enquanto a Catálise Básica e o Supercrítico apresentaram US\$ $13.354 .670,00$ e US\$ $12.587 .100,00$ respectivamente. Pode-se perceber que para os três casos o gasto com matérias-primas foi o fator dominante na composição dos custos, representando 74,6\%,67,1\% e 75,7\% para a catálise ácida, catálise básica e supercrítico respectivamente, dessa forma é crucial encontrar meios de diminuir o custo, principalmente, do óleo de macaúba e do etanol com o intuito de reduzir esses gastos. O gasto com óleo foi o mesmo para os três processos, pois a quantidade de entrada era fixa em $1000 \mathrm{~kg} \mathrm{~h}^{-1}$, já o gasto com etanol variou uma vez que era diferente a proporção etanol: óleo em cada processo e também pela porcentagem de recuperação que diferia entre eles. Mais uma vez o tamanho da planta operando por catálise básica influenciou de maneira negativa na composição dos custos, nota-se isso principalmente pelo elevado custo de mão de obra e suporte da planta, tornando-a a planta com maior custo operacional.

\subsection{Análise do Custo de Produção do Biodiesel}

Na Tabela 10 encontram-se os valores calculados para o MSP (preço mínimo de venda) das três plantas simuladas. Ao se observar os valores obtido, para cada processo temse que a planta operando por Catálise Ácida foi o que apresentou o menor e melhor resultado, o que já era esperado, uma vez que esta foi a de menor custo de investimento e de operação. O biodiesel possui preço comercial de 0,96 US\$ $\mathrm{kg}^{-1}$ (ALBUQUERQUE, 2015), ou seja, um valor notavelmente inferior ao obtido pelas três plantas simuladas, dessa forma seria necessário a presença de subsídios governamentais para que essas plantas pudessem alcançar esse preço de venda e se tornarem competitivas no mercado.

O glicerol produzido como coproduto da reação do biodiesel não entrou nas análises econômicas devido a sua baixa pureza e consequentemente baixo preço de mercado, 
entretanto este ajudaria a diminuir o custo de produção do biodiesel. Em caso de maneiras mais eficientes de se purifica-lo, isto é, processos mais baratos e com alta purificação, este apresentaria alto valor de mercado e tornaria-se um trunfo e viabilizaria o processo de produção de biodiesel independentemente de subsídios governamentais . Outra maneira de viabilizar a planta de produção seria através de uma integração energética mais eficiente, reduzindo dessa forma custos com utilidades.

Tabela 9 - Custos de operação das plantas simuladas.

\begin{tabular}{lrrr}
\hline & Custos de Operação (\$/ano) & \\
& Catálise & \multicolumn{1}{c}{ Catálise } & Supercrítico \\
& Ácida & \multicolumn{1}{c}{ Básica } & \\
\hline Custos de Suporte da Planta & $430.630,00$ & $852.548,00$ & $353.325,00$ \\
Mão de Obra & $832.770,00$ & $1.665 .540,00$ & $657.450,00$ \\
Geral e Administração & $880.675,00$ & $989.232,00$ & $932.378,00$ \\
Manutenção & $28.489,50$ & $39.556,60$ & $49.199,20$ \\
Óleo de Macaúba & $6.136 .166,26$ & $6.136 .166,26$ & $6.136 .166,26$ \\
Etanol & $2.336 .719,98$ & $1.875 .784,23$ & $3.398 .955,01$ \\
Ácido Sulfúrico & $278.972,42$ & $35.066,42$ & - \\
Óxido de Cálcio & $111.653,31$ & & - \\
Hidróxido de Sódio & - & $67.402,66$ & - \\
Ácido Fosfórico & - & $90.207,55$ & - \\
Água & 211,13 & 211,13 & - \\
Glicerina & - & $761.772,23$ & - \\
Despesas de Operação & $208.193,00$ & $416.386,00$ & $164.363,00$ \\
Utilidades & $644.632,00$ & $424.757,00$ & $895.266,00$ \\
Total & $11.889 .100,00$ & $13.354 .670,00$ & $12.587 .100,00$ \\
\hline
\end{tabular}

Por fim, a redução dos custos com matérias-primas seria o fator preponderante no custo de produção, tendo em vista que para os três casos ela representa a maior parte das despesas.

Tabela 10 - Preço mínimo de venda do biodiesel para as três plantas simuladas.

\begin{tabular}{lc}
\hline Planta Simulada & MSP $(\mathrm{US} \$ / \mathrm{kg})$ \\
\hline Catálise Ácida & 1,50 \\
Catálise Básica & 1,77 \\
Supercrítico & 1,59 \\
\hline
\end{tabular}




\subsection{Análise de Sensibilidade}

As análises de variação paramétrica realizada para os três processos encontram-se nas figuras 6, 7 e 8, nesses gráficos o eixo horizontal representa a variação do MSP de acordo com o parâmetro escolhido já os eixos verticais representam os valores de MSP calculados. O caso A representa as situações na qual ocorreu a redução de um parâmetro, sendo para o preço do óleo uma redução de $25 \%$ e para a vazão de óleo de macaúba uma redução de $30 \%$, já o caso B representa situações nas quais variou-se os parâmetros nas mesmas proporções utilizadas anteriormente.

Os resultados obtidos, comprovaram que, de fato, a variação do preço das matériasprimas é fator preponderante para a redução do custo de produção do biodiesel. Uma redução de $25 \%$ no preço do óleo de macaúba apresentou grande variação no MSP de todos os processos. Com relação a variação na produção, tem-se que a variação de $30 \%$ na vazão de entrada de óleo impactou de maneira considerável apenas nos processos de catálise ácida e básica, o processo supercrítico mostrou-se pouco sensível a este parâmetro. No caso de aumento da vazão para a catálise ácida notou-se uma pequena variação no valor do MSP, diminuindo-o, já para a catálise básica o aumento da vazão diminuiu de forma consideravelmente o MSP. A diminuição da vazão elevou os custos de produção do biodiesel para todos os processos, em especial para a catálise ácida. Após a realização da variação paramétrica observou-se que todos demonstraram uma tendência de redução do MSP com a redução no custo do óleo de macaúba e também para o aumento da produção.

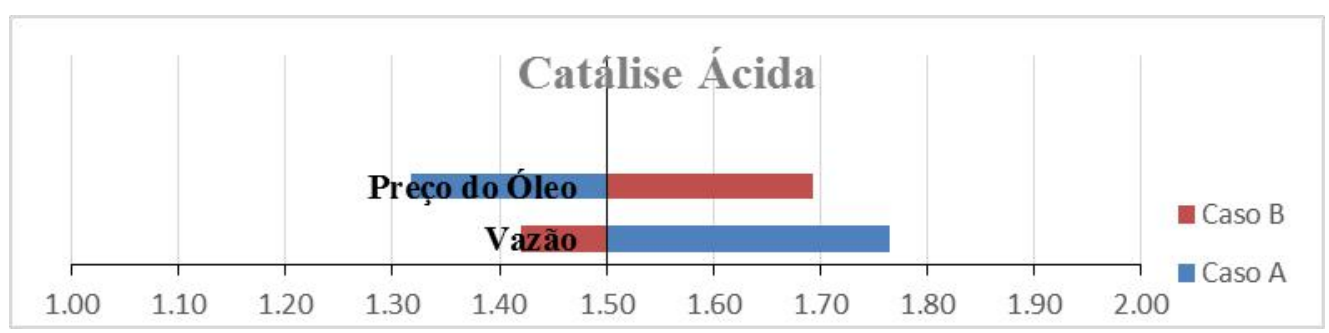

Figura 6 - Variação do MSP do biodiesel em função da variação do preço e da vazão do óleo.

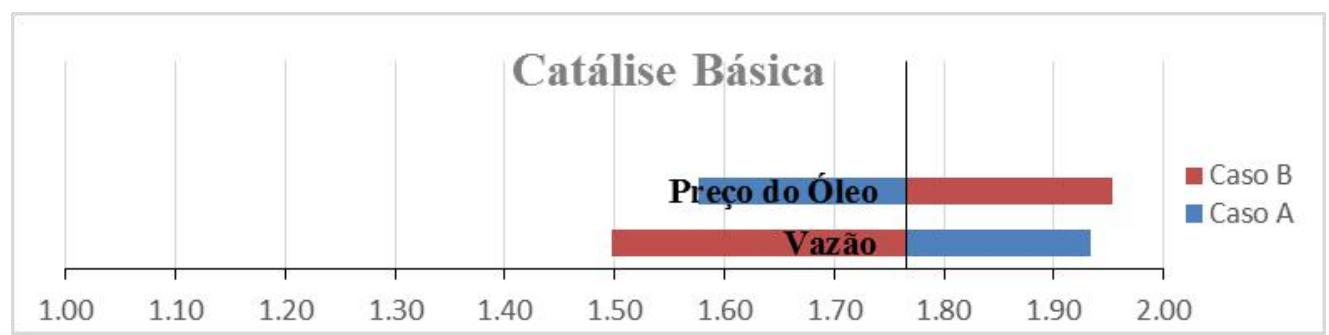

Figura 7 - Variação do MSP do biodiesel em função da variação do preço e da vazão do óleo. 


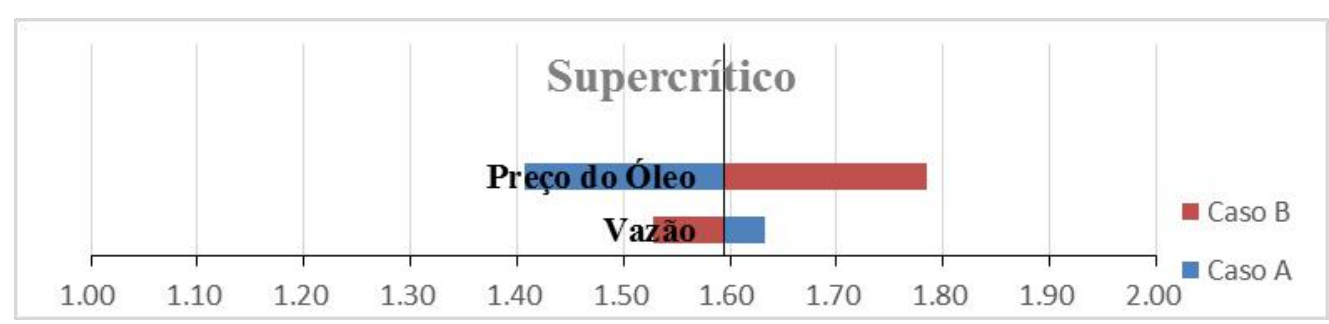

Figura 8 - Variação do MSP do biodiesel em função da variação do preço e da vazão do óleo.

\subsection{Estudo Comparativo}

A Tabela 11 exibe os custos de produção do biodiesel para diferentes matérias primas e rotas tecnológicas. Zhang et al. (2003) simularam a produção de biodiesel usando óleo virgem de canola e óleo residual, para o último caso os autores propuseram três processos. Dentre eles o melhor resultado obtido foi utilizando óleo residual como matéria prima através da rota ácida homogênea. Comparado aos valores encontrados para o biodiesel produzido a partir da macaúba, tem-se que os custos superiores deste deveram-se as diferenças de preço das matérias primas, sendo US\$200,00 para o caso do óleo residual (ZHANG et al., 2003) e US\$ 700,00 para o óleo de macaúba (NAVARRO-DÍAZ et al. 2014). A diferença de preços entre metanol e o etanol também impactou de forma significativa nos custo de produção, uma vez que o custo do etanol utilizado foi de US\$ 844 ton $^{-1}$ e o do metanol US\$180 ton ${ }^{-1}$. Haas et al.(2006) fizeram a transesterificação alcalina do óleo de soja e obtiveram US\$ 0,403 por quilograma de biodiesel. O preço do óleo de soja e do metanol, respectivamente de US\$ 520,00 ton $^{-1}$ e US\$ 286,00 ton ${ }^{-1}$, associados a alta produção anual justificam o baixo preço do biodiesel produzido. Em um estudo mais recente para óleos residuais Marchetti e Errazu (2008) conseguiram obter biodiesel a um custo de US\$ 350,00 por tonelada, comparado aos resultados de Zhang et al. (2003), os menores custos deveram-se a maior capacidade da planta. 
Tabela 11 - Custos da produção de biodiesel obtidos por diversos autores.

\begin{tabular}{|c|c|c|c|c|c|}
\hline Referências & $\begin{array}{l}\text { Produção } \\
\left(10^{3}\right. \\
\text { ton.ano-1) }\end{array}$ & $\begin{array}{l}\text { Matéria- } \\
\text { Prima }\end{array}$ & $\begin{array}{l}\text { Venda } \\
\text { do } \\
\text { glicerol } \\
\text { incluída }\end{array}$ & Rota & $\begin{array}{c}\text { Preço (US\$ } \\
\left.\mathrm{Kg}^{-1}\right)\end{array}$ \\
\hline \multirow{4}{*}{ Zhang et al. (2003) } & 8 & $\begin{array}{l}\text { Óleo virgem } \\
\text { canola }\end{array}$ & Sim & Alcalina Homogênea & 0,857 \\
\hline & 8 & $\begin{array}{c}\text { Óleo } \\
\text { Residual }\end{array}$ & Sim & $\begin{array}{l}\text { Alcalina Homogênea com } \\
\text { Pré-Tratamento }\end{array}$ & 0,884 \\
\hline & 8 & $\begin{array}{c}\text { Óleo } \\
\text { Residual }\end{array}$ & Sim & Ácida Homogênea & 0,644 \\
\hline & 8 & $\begin{array}{c}\text { Óleo } \\
\text { Residual }\end{array}$ & Sim & $\begin{array}{c}\text { Ácida Homogênea (Solvente } \\
\text { Hexano) }\end{array}$ & 0,702 \\
\hline Haas et al. (2006) & 33,31 & Óleo de Soja & Sim & Alcalina Homogênea & 0,403 \\
\hline $\begin{array}{l}\text { Marchetti e Errazu } \\
(2008)\end{array}$ & 36,04 & $\begin{array}{c}\text { Óleo } \\
\text { Residual }\end{array}$ & Sim & Alcalina Homogênea & 0,35 \\
\hline $\begin{array}{l}\text { Santana et } \\
\text { al.(2010) }\end{array}$ & 10,5 & $\begin{array}{l}\text { Óleo de } \\
\text { Mamona }\end{array}$ & Não & Alcalina Homogênea & 1,52 \\
\hline \multirow{2}{*}{$\begin{array}{l}\text { Young et al. } \\
\text { (2015) }\end{array}$} & 110,67 & Óleo de Soja & Sim & $\begin{array}{l}\text { Alcalina Homogênea com } \\
\text { Pré-Tratamento }\end{array}$ & 1,53 \\
\hline & 110,67 & $\begin{array}{l}\text { Óleo de } \\
\text { Dendê }\end{array}$ & Sim & $\begin{array}{c}\text { Alcalina Homogênea com } \\
\text { Pré-Tratamento }\end{array}$ & 1,62 \\
\hline
\end{tabular}

Santana et al. (2010) para o óleo de mamona e Young (2015) para o óleo de soja e de dendê obtiveram custos de produção próximos aos do óleo da macaúba, isso ocorreu principalmente por esses dois autores também aderirem a rota etílica e pela proximidade dos preços dos óleos, US\$ $1.157,00$ ton $^{-1}$ para a mamona, US\$ 879,00 ton $^{-1}$ para o óleo de soja e US\$ 869,00 ton ${ }^{-1}$ para o óleo de dendê.

\section{CONCLUSÃO}

Em todos os três processos se alcançou a pureza exigida para a comercialização e ao se fazer a análise econômica observou-se que o custo com matérias-primas foi predominante para todas as plantas. O glicerol, em nenhuma das três plantas, atingiu um nível elevado de pureza, dessa forma devido a seu baixo valor de mercado quando bruto ele não foi considerado nas análises econômicas. 
De acordo com a viabilidade econômica das três plantas, temos que a de catálise básica, apesar de apresentar como principal característica a capacidade de atuar em condições amenas apresentou o pior resultado, a razão disso foi a necessidade de uma etapa de prétratamento tendo em vista a acidez acentuada do óleo de macaúba, essa etapa encareceu de forma significativa os custos de investimento e operação. A planta supercrítica, apesar de ser um processo mais simples em termos de purificação e também pela ausência de gastos com catalisadores, apresentou fortes chances de ter o melhor desempenho, ainda assim não foi a melhor, uma vez que, por necessitar operar em altas pressões e temperaturas, ela demandou gastos muito maiores com equipamentos e tubulações capazes de lidar com essas condições. Outro fator que justifica esse processo não ser o melhor reside em ele ser o processo com menor recuperação de etanol, escalando assim os custos com essa matéria-prima de forma considerável se comparado com os demais. Por fim, teve-se que a planta operando por catálise ácida apresentou o melhor resultado, uma vez que demandou o menor custo de investimento e também de instalação fazendo com que dessa forma obtivesse o melhor MSP.

A variação paramétrica confirmou a necessidade de se reduzir os gastos com matériaprima, principalmente com o óleo de macaúba e também evidenciou que o custo de produção de biodiesel está diretamente ligado ao seu volume produzido. Dessa forma, em um cenário onde ocorra grande oferta de óleo de macaúba, com preços inferiores aos praticados hoje,essas plantas poderiam se tornar competitivas tendo em vista a economia nos gastos com matérias primas e também ao aumento da produção com isso reduzindo os custos associados a ela e promovendo uma economia de escala. A redução no preço do etanol e a realização de uma integração energética também poderiam impactar de forma significativa na redução dos custos.

\section{REFERÊNCIAS}

AlbuQuerque, A. A. Processo Alternativo de Produção de Biodiesel a partir de Matérias-Primas com Alto Teor de Ácidos Graxos Livres.2015.155f.Dissertação (Mestrado em Engenharia Química) - Universidade Federal de Pernambuco. CTG. Programa de Pós-Graduação em Engenharia Química, 2015.

ARANDA, D. A. G. et al. Acid-Catalyzed Homogeneous Esterification Reaction for Biodiesel Production from Palm Fatty Acids. Catalysis Letters, v. 122, n. 1-2, p. 20 25, 1 Abr 2008. Disponível em: <http://link.springer.com/10.1007/s10562-007-9318-z>. Acesso em: $11 \mathrm{dez} 2016$.

CARVALHO, A. et al. Estudo da pontecialidade da macaúba para produção de bioenergia. p. 5-6, 2013.

Centro de Estudos Avançados em Economia Aplicada (Cepea/Esalq). Disponível em: < http://www.cepea.esalq.usp.br/br/indicador/etanol.aspx>. Acesso em $17 \quad 04$ de novembro de 2016.

CHOI, C. S. et al. Transesterification kinetics of palm olein oil using supercritical methanol. The Journal of Supercritical Fluids, v. 58, n. 3, p. 365-370, Out 2011. Disponível em: <http://linkinghub.elsevier.com/retrieve/pii/S0896844611002592>. Acesso em: $11 \mathrm{dez} 2016$.

DABDOUB, M. J. e BRONZEL, J. L. Biodiesel: visão crítica do status atual e 
perspectivas na academia e na indústria. Quim. Nova, v. 32, n. 3, p. 776-792, 2009.

DEL RÍO, J. C. et al. Chemical composition and thermal behavior of the pulp and kernel oils from macauba palm (Acrocomia aculeata) fruit. Industrial Crops and Products, v. 84, p. 294-304, Jun 2016. Disponível em: $<$ http://linkinghub.elsevier.com/retrieve/pii/S0926669016300863>. Acesso em: $11 \mathrm{dez}$ 2016.

DEMIRBAS, A. Biodiesel : a realistic fuel alternative for diesel engines. [S.1.]: Springer, 2008.

FERREIRA, E. A. B. et al. Estimativa de Sequestro de Carbono numa População Espontânea de Palmeiras Macaúba. In: $8^{\circ}$ Congresso Internacional de Bioenergia São Paulo - Sp - 05 A 07 de Novembro de 2013.

GARCÍA, M. et al. Prediction of normalized biodiesel properties by simulation of multiple feedstock blends. Bioresource Technology, v. 101, n. 12, p. 4431-4439, 2010.

HAAS, M. J. et al. A process model to estimate biodiesel production costs. Bioresource Technology, v. 97, n. 4, p. 671-678, 2006.

GIRARDI, J.S. Produção de Biodiesel por Processo não Catalítico com Etanol Supercrítico a partir do Óleo de Tungue (Vernicia fordii) Bruto e in situ .2015.197f. Tese (Doutorado em Engenharia Química)- Centro Tecnológico. Universidade Federal de Santa Catarina, Florianópolis. 2015.

LOREnZI, G. M. A. C.; NEGRELle, R. R. B. Acrocomia Aculeata (Jacq.) Lodd. Ex Mart. : Aspectos Ecológicos, Usos e Potencialidades. Visão Acadêmica (Curitiba), v. 7, 2006.

MACHADO, S. A. Estudo da Produção de Biodiesel a partir do Óleo de Macaúba (Acrocomia aculeata). 2012. 135f. Dissertação (Mestrado em Engenharia Química), Escola de Engenharia de Lorena da Universidade de SãoPaulo, 2012.

MARCHETTI, J. M. e ERRAZU, A. F. Technoeconomic study of supercritical biodiesel production plant. Energy Conversion and Management, v. 49, n. 8, p. 2160-2164, 2008.

NAVARRO-DÍAZ, H. J. et al. Macauba oil as an alternative feedstock for biodiesel: Characterization and ester conversion by the supercritical method. The Journal of Supercritical Fluids, v. 93, p. 130-137, 2014.

PIMENTEL L. D. et al. Coeficientes técnicos e Custos de Produção do Cultivo da Macaúba. Inf. Agropecu. (Belo Horizonte) 2011;n 32; p. 61-69.

QUINTANA,L.G. et al. Liberação de Nutrientes Durante a Decomposição de Resíduos Vegetais de Macaúba em Áreas com Variações de Lençol Freático.In: $8^{\circ}$ Congresso Internacional de Bioenergia São Paulo - Sp - 05 A 07 de Novembro de 2013

RAMADHAS, A. S. e JAYARAJ, S. e MURALEEDHARAN, C. Use of vegetable oils as I.C. engine fuels-A review. Renewable Energy, v. 29, n. 5, p. 727-742, Abr 2004. Disponível em: <http://linkinghub.elsevier.com/retrieve/pii/S0960148103002982>. Acesso em: $11 \mathrm{dez} 2016$.

SANTANA, G. C. S. et al. Simulation and cost estimate for biodiesel production using castor oil. Chemical Engineering Research and Design, v. 88, n. 5, p. 626-632, 2010.

SHAFIEE, S. e TOPAL, E. When will fossil fuel reserves be diminished? Energy Policy, v. 37, n. 1, p. 181-189, 2009.

TORRES, P. Z. Simulação do processo de produção de biodiesel usando etanol supercrítico. 2015.54 f. Trabalho de Conclusão de Curso - Escola de Engenharia de Lorena, Universidade de São Paulo, Lorena, 2015. 
VELEZ, A. e colab. Continuous production of fatty acid ethyl esters from sunflower oil using supercritical ethanol. Fuel, v. 97, p. 703-709, 2012.

VIEITEZ, I. et al. Effect of Free Fatty Acids on the Efficiency of the Supercritical Ethanolysis of Vegetable Oils from Different Origins. Energy \& Fuels, v. 26, n. 3, p. 1946-1951, $15 \quad$ Mar 2012. Disponível em: $<$ http://pubs.acs.org/doi/abs/10.1021/ef201977s >. Acesso em: $11 \mathrm{dez} 2016$.

WEST, A. H. e POSARAC, D. e ELLIS, N. Assessment of four biodiesel production processes using HYSYS.Plant. Bioresource technology, v. 99, n. 14, p. 6587-601, Set 2008. Disponível em: <http://www.ncbi.nlm.nih.gov/pubmed/18234493>. Acesso em: $11 \mathrm{dez} 2016$.

YOUNG, A. F. e PESSOA, F. L. P. e QUEIROZ, E. M. Comparison between Biodiesel Production from Soybean Oil and Palm Oil with Ethanol: Design and Economic Evaluation. Chemical Engineering Transactions, v. 43, n. May, p. 325-330, 2015.

ZHANG, Y. et al. Biodiesel production from waste cooking oil: 1. Process design and technological assessment. Bioresource Technology, v. 89, n. 1, p. 1-16, 2003. 


\title{
SIMULATION AND ECONOMIC ANALYSIS OF BIODIESEL PRODUCTION FROM MACAUBA OIL
}

\author{
R. P. CRUZ ${ }^{1}$, F.B. FERREIRA ${ }^{2}$ e F.Á RODRIGUES ${ }^{3}$ \\ (um espaço SIMPLES) \\ ${ }^{1}$ Universidade Federal de Viçosa, Departamento de Química \\ ${ }^{2}$ Universidade Federal de Viçosa, Departamento Química \\ ${ }^{3}$ Universidade Federal de Viçosa, Departamento de Química \\ E-mail: rodolfo_pinheiro@hotmail.com
}

\begin{abstract}
This work had the objective to simulate three different biodiesel plants using the ethyl route and macauba oil as the source of triglycerides, all of them were simulated using the software Aspen HYSYS 8.8. The plants were designed to operate using an oil flow rate of $1000 \mathrm{~kg} \mathrm{~h}-1$ and the routes selected were homogeneous acid catalysis, homogeneous alkali catalysis and supercritical method. The biodiesel produced has reached the purity requirements from both the Brazilian agency Agência Nacional do Petróleo(ANP) and the American Society for Testing and Materials (ASTM). An economic analysis was also made for each plant to estimate biodiesel production cost. The biodiesel production cost for the homogeneous acid catalysis, homogeneous alkali catalysis and a supercritical method plants were US\$1.50, US\$1.77 and US\$1.59, respectively. Finally a parametric analysis was made to observe the effects of the variation of flow rate and price of macauba oil over the biodiesel production costs.
\end{abstract}

KEYWORDS: Biodiesel; Macauba oil; Ethanol; Aspen HYSYS; Simulation; Economic analysis. 